\title{
Carnap versus Quine, or Aprioristic versus Naturalized Epistemology, or a Lesson from Dispositions
}

\author{
Wolfgang Spohn \\ Fachbereich Philosophie \\ Universität Konstanz \\ 78457 Konstanz \\ Germany
}

\section{Introduction*}

The philosophical differences between Carnap and Quine were vast and principled in the end, or perhaps they only appeared so because the two were so close and because the points of divergence are so clearly traceable. Presently, the prevailing impression is that Quine has won the day, surely also simply because Quine survived Carnap by almost 30 years. Indeed, Carnap has lapsed, it seems, into what is only the historic background of the present situation.

It is idle to speculate how philosophy would look today if Carnap had lived longer; certainly he would have changed as well. In any case, this paper intends to counteract the prevailing impression. There are quite a number of Carnapian ways which I would like to defend against the corresponding Quinean moves. In this short paper, however, I focus on a single aspect, though a central and, I find, particularly compelling one. Hence, it will at least suggest a general lesson. To establish the lesson in full depth would, however, require a lot more of work and space.

The aspect I have in mind concerns dispositions - a topic which was in the center of the old epistemological discussions guided by the hope to reconstruct the overall structure of the concepts and contents of our scientific world view. It is well known what the logical positivists or empiricists had to say about dispositions. They were not satisfied by what they had to say, they changed their mind several times, and they did not arrive at a doctrine which they could fully endorse. ${ }^{1}$ Grounds being

\footnotetext{
* I am indebted to Thomas Bonk for various valuable hints and remarks.

${ }^{1}$ Cf. in particular Carnap (1936/37 and 1956).
} 
shaky, Quine's (1951) criticism of the notion of analyticity proved to be very effective. Hence, Quine (1969) could eventually draw the conclusion and bury logical empiricism more deeply than ever before. Indeed, that paper has become something like the founding act of so-called naturalized epistemology, which presently seems to be the predominant attitude towards epistemology. ${ }^{2}$

The problem of dispositions was indeed an essential step in that paper. I quote from Quine (1969):

„He [Carnap] was seeking what he called a rational reconstruction. Any construction of physicalistic discourse in terms of sense experience, logic, and set theory would have been seen as satisfactory if it made the physicalistic discourse come out right. If there is one way there are many, but any would be a great achievement.“"(p.75)

„We must despair of any such reduction. Carnap had despaired of it by 1936, when, in „Testability and meaning“, he introduced so-called reductions forms of a type weaker than definition.“(p.77)

„To relax the demand for definition, and settle for a kind of reduction that does not eliminate, is to renounce the last remaining advantage that we supposed rational reconstruction to have over straight psychology ... If all we hope for is a reconstruction that links science to experience in explicit ways short of translation, then it would seem more sensible to settle for psychology. Better to discover how science is in fact developed and learned than to fabricate a fictitious structure to a similar effect.“ (p.78)

We may indeed have to renounce Carnap's reductionism. Still, I find Quine's conclusion premature. In order to explain this, I have to introduce some epistemological preliminaries in section 2 . Section 3 is devoted to the classical view of dispositions. In section 4 I sketch my recent view of dispositions, which suggests, in section 5, the reconsideration of Carnap's aprioristic as opposed to Quine's naturalized epistemology.

\section{Dynamics of Belief and Apriority}

For me it is not the theory of knowledge, but rather the theory of belief which is in the center of epistemology. That theory should indeed be conceived more generally as the theory of doxastic states. Like any good theory about a subject matter this theory has the basic task of developing the statics and the dynamics of doxastic

\footnotetext{
${ }^{2}$ One should note, though, that this attitude has rather started with Lorenz (1941), i.e., with the evolutionary epistemology he and his congenials developed. One should also note that Quine has apparently changed his mind. In (1995), pp. 49f., he gives much more space to normative epistemology than ever before and thus softens his naturalistic attitude.
} 
states. These tasks are not independent, of course; static models of doxastic states must be conceived so as to allow for a good dynamic theory.

Probability theory provides the paradigm theory of the statics and the dynamics of doxastic states. Indeed, Carnap has made important contributions to this paradigm with his incessant efforts towards constructing an inductive logic since his (1950). However, in the last 25 years the field exploded; and a considerable variety of alternative theories, like AGM belief revision theory, ranking theory, default logic, etc., have been developed, which were particularly concerned with the dynamics of what I call plain belief, according to which the objects of belief, or propositions for short, are accepted as true, or rejected as false, or judged neutrally. ${ }^{3}$ Carnap did not live long enough to see these developments, and I have no evidence that they had any influence on Quine's writings (although Quine, Ullian (1970) was an informal predecessor of that literature).

It is not the place here to go into any details. But for all I know, all these theories, probability theory and its alternatives, have a notion of degrees of belief (if degrees are here understood in a sufficiently wide sense) and indeed a notion of conditional degrees of belief. It is these conditional degrees that allow to formulate a dynamics of doxastic states via the usual conditionalization rules or more sophisticated alternatives.

More important for the present purpose are two immediate philosophical applications of my emphasis on the dynamics of belief. One is this: Within a rationalistic picture of our cognitive constitution one would say that the dynamics of our beliefs is driven by the reasons and counter-reasons we receive. But what are reasons? Well, a proposition $A$ is a reason for another proposition $B$ according to a given doxastic state if and only if $A$ supports or confirms $B$, or if $A$ speaks for $B$, or if $A$ strengthens the belief in $B$, or, more formally, if the degree of belief in $B$ is higher given $A$ than given non- $A$, i.e., if $A$ is positively relevant for $B$. And correspondingly for counter-reasons. Thus, it is precisely the reasons and counter-reasons for $B$ we receive which make us change our degree of belief in $B$. Of course, this notion of a reason is just Carnap's old notion of confirmation, which makes thus wider than only probabilistic sense. ${ }^{4}$

\footnotetext{
3 Concerning belief revision theory cf., e.g., Gärdenfors (1988) and Rott (2001), concerning ranking functions, then called ordinal conditional functions, cf. Spohn (1988), and concerning an overview over what is on offer cf. Gabbay et al. (1994).

${ }^{4}$ Cf. Carnap (1950, ch. VI) and in particular the preface to the second edition, pp. xv - xx. For reasons within the framework of ranking functions cf. Spohn (1991).
} 
The other application is that the notion of apriority immediately springs from the dynamics of belief, or rather two notions of apriority which we must carefully distinguish. The full importance of the second notion was, it seems, not recognized by Carnap and Quine, but we shall see that it is this second notion which sheds new light on dispositions.

The first notion is this: Obviously, a doxastic state can have various features or properties such as that, according to it, $A$ has a high degree of belief, or a higher degree of belief than $B$, etc. Now we call any such feature of a doxastic state unrevisably a priori if and only if it is a necessary feature, i.e., if each possible doxastic state capable of having this feature has this feature - where a doxastic state is capable of having this feature if and only if it has acquired the concepts involved in that feature. As the label indicates, apriority in this sense is unrevisability.

This talk of a priori features may sound very abstract. Isn't it propositions which are a priori? Yes, of course, this is a special case. Among the many features a doxastic state may have, one is the belief in a proposition. Thus, a proposition is unrevisably a priori, if it is necessarily believed in each doxastic state capable of believing this proposition at all, i.e. grasping the concepts involved in this proposition. But, as mentioned, there are other features such as the one that $A$ is a reason for $B$ according to a doxastic state, and we may well wonder about the apriority of such other features, too. Indeed, this suggestion will become relevant later on.

Quine (1951) put forward two criticisms of the notion of analyticity. The second was that there are indeed no unrevisable statements at all. So, this was rather a criticism of apriority. ${ }^{5}$ The issue is a large one, so I can cetainly not dispel Quine's criticism here. But one should note that he argues for the universal revisability of statements as linguistic forms, and then he may well be right if the statements change their meaning during the revision. With meanings fixed, however, I can't see how the truths of classical logic or the Cartesian examples „I exist now“ or „I am here now" could ever be revisable; and there are many more examples. Of course, Quine would insist that in noticing this I am begging the question, because he has shown the illegitimacy of talking of fixed meanings. That's why I said I can't refute Quine here (though I believe that it is possible to make sense of constancy and changes of meaning). But since the lessons taught by the failing explications of disposition predicates were one major ingredient of his holistic picture of empirical

\footnotetext{
5 Thus, Quine continued the logical empiricists ‘ confusion of analyticity and apriority, as has already been noted by Putnam (1976).
} 
significance and thus of his claims about revisability, I think this paper may eventually undermine his view from my opposing starting point.

The other notion of apriority is this: A feature of a doxastic state is defeasibly a priori if and only if each initial doxastic state capable of having this feature has it. It should be clear again that it may be propositions believed as well as other features which may be a priori in this sense. The crucial term here is ,initial“. It means something like "before any evidence or experience relevant to the feature or proposition in question has been acquired". That is, an initial state capable of having the relevant feature is one which has only acquired the concepts involved in that feature, but no further information. ${ }^{6}$

There is a venerable example for defeasible apriority, namely a priori probabilities distributed equally according to the so-called principle of insufficient reason or various symmetry or indifference postulates which acquired such a crucial role in Carnap's inductive logic. They are defeasibly a priori (though Carnap did not call them so), because further information may break the symmetry; we only have to start with them.

Quine (1960, sect. 9 and 14) has already criticized this notion by arguing that there is no way to distinguish the information necessary to acquire a concept from what he called collateral information. To use one of his examples ${ }^{7}$ : everybody who has acquired the notion of a dog would agree that there are dogs, but as he says, it would be absurd to say that it is analytic that there are dogs. Yes, indeed. But he is actually giving here a nice example for the defeasible a priori. For each notion that is learned by ostension it is defeasibly a priori that this notion is instantiated, namely at least by the ostended paradigms. But this apriority may be defeated; it may still turn out, though only under unusual circumstances ${ }^{8}$, that the relevant notion was only erroneously believed to be instantiated. (This defeasible apriority seems to me to be the grain of truth in the famous paradigm-case argument; cf. Watkins (1957/58) and the other papers collected in that Analysis volume.)

\footnotetext{
6 The distinction of the two notions of apriority is quite common by now. For instance, Pollock (1986) emphasizes that there are not only conclusive reasons, but also defeasible or prima facie reasons. This is just my distinction applied to reasons (though his notion of a reason differs from mine). Similarly, Field (1996) distinguishes weak apriority, which is believability justifiable on a basis other than empirical evidence, and strong apriority, which adds empirical indefeasibility to the weak form.

7 Cf. Quine (1969, p.86).

${ }^{8}$ One may well first acquire the notion of a witch ostensively and thus at the same time the belief that there are witches and then learn that to be possessed by the devil is an essential feature of witches and that since there is no devil there are no witches. Or one may learn "flat" by ostension and realize later on that nothing on Earth is really flat.
} 
Hence, as I said, it appears that Quine did not realize the importance of defeasible apriority and that Carnap recognized it only within the special context of his inductive logic. In what follows we shall see that its significance extends further.

\section{Disposition Predicates and Reduction Sentences}

So far for my preliminaries. Let us see now how they might help with dispositions, and let me start my discussion by briefly recapitulating why dispositions are so problematic.

A disposition predicate like „,soluble“, „magnetic“, „dormative“, or „,red“ denotes a property instantiated by an object just in case it shows appropriate behavior in appropriate test situations. For instance, an object is soluble if and only if it would dissolve if put into water. How this should be precisely understood, however, turned out to be a highly persistent problem.

The logical positivists thought that the non-given must somehow be reduced to, or constructed from, the given; thus, non-observational predicates had to be defined in terms of observational ones. „Soluble“, for instance, is not observational. One does not immediately see whether something is soluble; this is manifested only in special circumstances. For the sake of the example, let us assume that ,put into water“ and „dissolve“ are observational predicates. Now, when I have just defined:

(1) $x$ is soluble if and only if $x$ would dissolve if $x$ were put into water,

have I not given the desired definition? No, or at least not in a manner acceptable to the logical positivists. The reason is that the subjunctive in the defining condition is not yet explained and that we do not know therefore how to construct the truth condition of ,,$x$ is soluble“ from the truth conditions of , $x$ is put into water" and , $x$ dissolves". As mentioned above, the logical positivists despaired of this problem.

Carnap (1936/37) then looked for the second best, namely for stating, reduction sentences instead of definitions. In our example, the reduction sentence says:

(2) if $x$ is put into water, then $x$ is soluble if and only if $x$ dissolves.

The decisive advantage of (2) over (1) is that all ifs may now be understood as truthfunctional material implications; there is no unexplained subjunctive. Moreover, the reduction sentence is apparently true. The decisive drawback is that (2) gives only a 
conditional definition of solubility and hence no definition at all. We saw that this is the point which Quine found devastating. Indeed, it meant to give up the reductionist programme of the logical positivists.

Logical empiricism ${ }^{9}$ tried to turn this into a virtue by more modestly requiring only that the non-given is at least partially interpreted by the given, i.e., that nonobservational statements are connected with observation statements in such a way that the former acquire empirical significance and may be tested and confirmed by the latter. Thus vaguely put, this is certainly something everybody could agree.

A good example of such partial interpretation is the reduction sentence (2). It renders assertions about an object's solubility empirically significant and testable. Moreover, the truth of the reduction sentence cannot derive from empirical facts; the unanswerable question how the reduction sentence should in turn be tested and confirmed would make partial interpretation appear mysterious again. Indeed, the truth of the reduction sentence seems to immediately flow from the meaning of the predicates involved; that is, the reduction sentence seems to be analytic, as partial interpretation seems to require.

However, all this cannot be quite right, as the logical empiricists soon recognized. ${ }^{10}$ This is indicated by so-called multi-track dispositions which have more than one characteristic manifestation and are therefore characterized by several reduction sentences. These reduction sentences then imply purely observational statements which are clearly not analytic. Hence, not all reduction sentences can be analytic and, by symmetry; none of them can.

More important for Carnap (1956) was the insight that the reduction sentences of the form (2) are, strictly taken, false, even for one-track dipositions like „soluble“. There may be ever so many strange circumstances in which a soluble object put into water does not dissolve and vice versa. Maybe the water is already saturated, and the soluble object does not dissolve. Maybe a strong electric current is flowing through the water, and the insoluble object dissolves after all. And there are certainly many more bizarre physical possibilities and impossibilities decoupling disposition and manifestation.

Hence, the reduction sentence needs a little softening, say:

\footnotetext{
9 With Stegmüller (1970) I am used to distinguish earlier logical positivism and subsequent logical empiricism, even though the philosophers entertaining these positions were largely the same.

${ }^{10}$ Stegmüller (1970, ch. III-V) is still the canonical representation of this philosophical development and its ramifications.
} 
(3) If $x$ is put into water and normal conditions obtain, then $x$ is soluble if and only if $x$ dissolves.

It is as common as obscure to say that the reduction sentence is thereby subject to a ceteris paribus clause, which some believe to be constraining the whole of empirical science. So, in order to assess the status of the revised reduction sentence (3), our obvious task is to clarify this admittedly vague reference to normal conditions. ${ }^{11}$

\section{Normal Conditions and Reasons a priori}

To begin with, it is obviously the task of the empirical sciences to get rid of this vague reference as far as possible and to inquire what are normal and what are deviant conditions. This inquiry will result in a possibly quite long list of specific conditions. But precisely because of the empirical character of the inquiry there can be no analytic, but at most an empirical extensional equivalence between this list and our talk of normal conditions.

Another suggestion might be to define the normal conditions in (3) as those conditions under which all and only soluble objects dissolve when put in water. According to this suggestion reduction sentences such as (3) would simply be analytic. This is not the wrong result, as we shall see; but it would be wrong to derive it from the suggested definition which is inadequate; it is too generous since it takes very crazy conditions making (3) true by chance also to be normal.

The third idea is the most literal one; according to it normal conditions are exactly those conditions which normally, usually, or mostly obtain. That's vague, of course, but I shall worry about this only in a second step. Let us first observe that the reference to normal conditions must here be understood in a referential or rigidified and not in an attributive way. This is to say the following:

The meaning or intension of the word ,soluble“ is given by its extension in every possible world, and this extension has to satisfy the reduction sentence (3). When the attributive reading of the normal conditions is applied to (3) they would have to be understood as those conditions which are, respectively, normal in the possible world in which the extension is evaluated; this may vary from world to world. In a

${ }^{11}$ Ceteris paribus clauses and normal conditions pose another issue with which logical empiricists struggled inefficiently and which returned in the last 15 years with great help by the philosophy of mind. See Earman et al. (2002) and all the other papers in that Erkenntnis issue for the most recent and embracive discussion of the topic. 
referential or rigidified reading, by contrast, the normal conditions are those which are normal in our actual world. The latter is the reading we have to apply in (3), for the simple reason that the normal conditions referred to are not those usually obtaining in the entire universe, but those usually encountered by us in the small spacetime region we inhabit. Thus, normality is an indexical notion. This observation has two important consequences.

The first concerns the metaphysical status of normal conditions. When the empirical sciences come up with the above-mentioned list of specific conditions, this list is, if correct, necessarily equivalent with the normal conditions (a fact concealed by the vagueness of ,normally“, ,usually“, and „mostly“); there is no principled difference to other necessary identities like „Hesperus = Phosphoros“, ,water = $\mathrm{H}_{2} \mathrm{O}$ “ or , the boiling temperature of water (here and now, rigidified) $=100^{\circ} \mathrm{C}$ “"

The second observation concerns the epistemological status of the modified reduction sentence (3). If the normal conditions are read referentially, (3) is unrevisably a priori; it cannot turn out to be false. For, wherever in the actual world an object dissolves in water despite being insoluble or does not dissolve despite being soluble, normal conditions do obviously not obtain (this is not to say, as we shall see in a moment, that normal conditions would be defined in this way); this much we know even if we know very little about the actual normal conditions. Similarly, we know unrevisably a priori that the inventor of the light bulb (rigidified) invented the light bulb, even if we know nothing else about that inventor.

Thereby, however, we have still insufficiently captured the epistemological role of our talk of normal conditions. Up to now normal conditions as well as proposition (3) have remained disturbingly vague. How could it be that something as vague as (3) is unrevisably a priori? Referring to my epistemological preliminaries I would like to suggest that this knowledge is grounded in an a priori justificatory relation. Instead of saying that the reduction sentence (3) including its reference to normal conditions is unrevisably a priori, I propose the following reformulation that avoids reference to normal conditions ${ }^{12}$ :

(4) Given that $x$ is put into water, the assumption (or proposition) that $x$ is soluble is a priori a (sufficient ${ }^{13}$ ) reason for assuming that $x$ dissolves, and vice versa.

\footnotetext{
12 The line of reasoning I am presenting in this section is more fully explained in Spohn (1997).

13 Within the framework of ranking functions (unlike the probabilistic framework) we can distinguish sufficient and necessary reasons (and other kinds). Cf. Spohn (1991).
} 
How is the ,a priori” to be understood in (4)? Obviously, the relation of confirmation or positive relevance can here be only initially given and not forever fixed, since it is always possible that relevant data emerge conditional on which the solubility of an object is not a reason for, and maybe even a reason against, its dissolution if put into water. The space of further reasons, counter-reasons and relevant conditions can only be unraveled by further inquiry. That the justificatory relation in (4) is a priori can therefore only mean that it obtains initially as long as nothing else is known; i.e., it is defeasibly a priori.

Since considering $A$ to be a sufficient reason for $B$ implies believing in the material conditional $A \rightarrow B^{14}$, it follows from (4) that the unqualified reduction sentence (2) is also defeasibly a priori, in remarkable contrast to the qualified reduction sentence (3) which we found to be unrevisably a priori. This contrast allows us to improve our understanding of normal conditions: they are precisely those conditions under which the initially given justificatory relation can be maintained and is thus confirmed.

This is stricter than to say that the normal conditions are those under which that justificatory relation obtains, because this would include multiply exceptional conditions under which the justificatory relation is first lost and then reestablished. The stricter account seems more adequate. In any case, no claim is thereby made about what the normal conditions actually are; to find out about this is up to science. Yet the epistemological role of normal conditions is thereby sufficiently accounted for. ${ }^{15}$

This account finally explains the respective apriority of (2) and (3). The assumption that normal conditions obtain is the a priori default assumption with which we are always bound to start; hence, (2) is also defeasibly a priori. Furthermore, if the normal conditions are those under which the positive relevance stated in (4) continues to hold, then the normal conditions cannot be enriched in such a way that the positive relevance is invalidated; hence, (3) is unrevisable. ${ }^{16}$

\footnotetext{
14 The converse does not hold!

15 In Spohn (2002) I give a more formal version of this account of normal conditions in terms of ranking functions.

${ }^{16}$ How (4) develops from (1) via (2) and (3) should have been sufficiently clear. However, it has turned out (cf. Martin 1994) that (1) is the wrong starting point. A disposition can be finkish, i.e., it can vanish just when and because it is put into a test situation in which it should prove itself. In such cases an object has a disposition even though the corresponding conditional (1) is false. (Cf. Lewis 1997 for more complicated cases.) Does this impair (4)? I don't think so:

We have to distinguish two cases. The first is that the test situation in which the disposition is finkish is rare. In this case (4) holds true, and we have to learn that the finkish situation belongs to exceptional circumstances in which the disposition is present, though the manifestation fails.
} 


\section{Conclusion}

Clearly, the account of disposition predicates just sketched is neither psychology nor naturalized epistemology. Hence, I did not follow Quine's advice. Also, my account did not offer a definition or analytic reduction of dispositions to observables. In that respect I did not confirm Carnap's position, either.

However, the implicit background of my account was the framework of twodimensional semantics which David Kaplan and Robert Stalnaker started developing from Carnap's intensional semantics ${ }^{17}$ and which embraces metaphysical as well as epistemic modalities. ${ }^{18}$ Within this framework the notion of reduction has become ambiguous; it may refer to the metaphysical or the epistemic dimension. Indeed, the only reduction which may be feasible with respect to dispositions is the metaphysical one according to which a disposition supervenes on or is identical with its causal base. ${ }^{19}$ But even if I have discarded epistemic and hence analytic reduction, I have saved the a priori, by explaining what is in which sense a priori about disposition predicates. Insofar it is aprioristic epistemology which I have presented here.

It is idle to speculate whether Carnap would have agreed. But it seems clear to me that my account is much more Carnapian in spirit than Quinean. ${ }^{20}$ Thus I wonder whether it is suited to stimulate a more general revival of Carnap's attitude towards epistemology.

The other case is that the disposition of an object to show response $R$ is always or mostly finkish in the test situations in which it might prove. In this case, it is perhaps not so clear whether the object really has the disposition to show response $R$ (though Lewis 1997, pp.147f., thinks so). Certainly, the whole arrangement does not have the disposition to display $R$ (even if the object as such has the disposition which is then thwarted by the rest of the arrangement). But then (4) rightly applies again when its $x$ is taken to refer to the whole arrangement.

17 For a detailed presentation of two-dimensional semantics see Haas-Spohn (1995).

18 In Spohn (1997) I have explicitly placed my analysis of dispositions within this framework.

19 Ironically, this idea seems first to surface in Quine (1960, §46).

${ }^{20}$ As I mentioned in footnote 2, Quine (1996) acknowledged normative epistemology more frankly than in his earlier naturalistic writings. However, I discovered no indication of a return to the a priori. 


\section{References}

Carnap, Rudolf, „Testability and Meaning“, in: Philosophy of Science 3, 1936, pp.419-471 and 4, 1937,pp. 1-40.

Carnap, Rudolf, Logical Foundations of Probability, Chicago: Chicago University Press 1950.

Carnap, Rudolf, „The Methodological Character of Theoretical Concepts“, in: Herbert Feigl, Michael Scriven (eds.), Minnesota Studies in the Philosophy of Science, vol. I, Minneapolis: University of Minnesota Press 1956, pp.38-76.

Earman,John, John Roberts, Sheldon Smith, „Ceteris Paribus, the Emperor has no Clothes", to appear in Erkenntnis 57, 2002.

Field, Hartry, „The A Prioricity of Logic“, Proceedings of the Aristotelian Society 96, 1996, 359-379.

Gabbay, Dov M., Christopher J. Hogger, John A. Robinson (eds.) (1994), Handbook of Logic in Artificial Intelligence and Logic Programming, vol. 3, Nonmonotonic Reasoning and Uncertainty Reasoning, Oxford: Oxford University Press.

Gärdenfors, Peter, Knowledge in Flux. Modeling the Dynamics of Epistemic States, Cambridge, Mass.: MIT Press 1988.

Haas-Spohn, Ulrike, Versteckte Indexikalität und subjektive Bedeutung, Berlin: Akademie-Verlag 1995.

Lewis, David, „Finkish Dispositions“, in: Philosophical Quarterly 47, 1997, pp.143-158.

Lorenz, Konrad, „Kants Lehre vom Apriorischen im Lichte gegenwärtiger Biologie”, in Blätter für Deutsche Philosophie 15, 1941, pp.94-125.

Martin, Charles B., „Dispositions and Conditionals“, in: Philosophical Quarterly 44, 1994, pp.18.

Pollock, John L., Contemporary Theories of Knowledge, Savage: Rowman \& Littlefield 1986.

Putnam, Hilary, ,'Two Dogmas’ Revisited“, in: G. Ryle (ed.), Contemporary Aspects of Philosophy, London: Oriel Press 1976, pp.202-213.

Rott, Hans, Change, Choice, and Inference, Oxford: University Press 2001.

Quine, Willard Van Orman, „Two Dogmas of Empiricism", in: Philosophical Review 60, 1951, pp.20-43.

Quine, Willard Van Orman, Word and Object, Cambridge, Mass.: MIT Press 1960.

Quine, Willard Van Orman, „Epistemology Naturalized", in: W.V.O. Quine, Ontological Relativity and Other Essays, New York: Columbia University Press 1969, pp.69-90.

Quine, Willard Van Orman, Joseph S. Ullian, The Web of Belief, New York: Random House 1970.

Quine, Willard Van Orman, From Stimulus to Science, Harvard: University Press 1995.

Spohn, Wolfgang, ,Ordinal Conditional Functions. A Dynamic Theory of Epistemic States", in: William L. Harper, Brian Skyrms (eds.), Causation in Decision, Belief Change, and Statistics, vol. II, Dordrecht: Kluwer 1988, pp.105-134.

Spohn, Wolfgang, „A Reason for Explanation: Explanations Provide Stable Reasons“, in: Wolfgang Spohn, Bas C. van Fraassen, Brian Skyrms (eds.), Existence and Explanation, Dordrecht: Kluwer 1991,.pp.165-196.

Spohn, Wolfgang, „Begründungen a priori - oder: ein frischer Blick auf Dispositionsprädikate“, in: Wolfgang Lenzen (ed.), Das weite Spektrum der Analytischen Philosophie. Festschrift für Franz von Kutschera, Berlin: de Gruyter 1997, pp.323-345.

Spohn, Wolfgang, „Laws, Ceteris Paribus Conditions, and the Dynamics of Belief“, to appear in Erkenntnis 57, 2002.

Stegmüller, Wolfgang, Probleme und Resultate der wissenschaftstheorie und Analytischen Philosophie, Band II, Theorie und Erfahrung, 1. Teilband, Berlin: Springer 1970.

Watkins, John W. N., „Farewell to the Paradigm-Case Argument", in: Analysis 18, 1957/58, pp. 25-33. 